\title{
Cauliflower-like deformation of pulmonary valve in a case of infective endocarditis by a rare organism: Gemella morbillorum
}

\author{
Navin Agrawal, Mallesh Kariyappa, Vikram B Kolhari, \\ Cholenahally Nanjappa Manjunath
}

Department of Cardiology, Sri Jayadeva Institute of Cardiovascular Sciences and Research, Bangalore, Karnataka, India

\section{Correspondence to} Dr Navin Agrawal, drnavinagrawal@gmail.com

Accepted 16 April 2014
CrossMark

To cite: Agrawal $\mathrm{N}$ Kariyappa M, Kolhari VB, et al. BMJ Case Rep Published online: [please include Day Month Year] doi:10.1136/bcr-2014204726

\section{DESCRIPTION}

Infective endocarditis often presents with vegetations attached to the surface of the valve leaflets and sometimes with structural damage of the valves in the form of perforation of the leaflets or in the form of valvular or perivalvular abscesses. Sometimes smouldering infection can damage the valve structure and can cause deformation of the valve structure to such an extent that it conforms abnormal shapes.

We report a rare case of a middle-aged person with a previously undiagnosed atrial septal defect (ASD) who presented with symptoms of progressively worsening exertional fatigue and dyspnoea. The patient had a history of being treated for infective endocarditis by a rare Gram-positive cocci Gemella morbillorum which was previously known as Streptococcus morbillorum.

The patient was evaluated and found to have severe pulmonary regurgitation and the grossly deformed valve was also causing significant stenosis across the right ventricular outflow tract. The

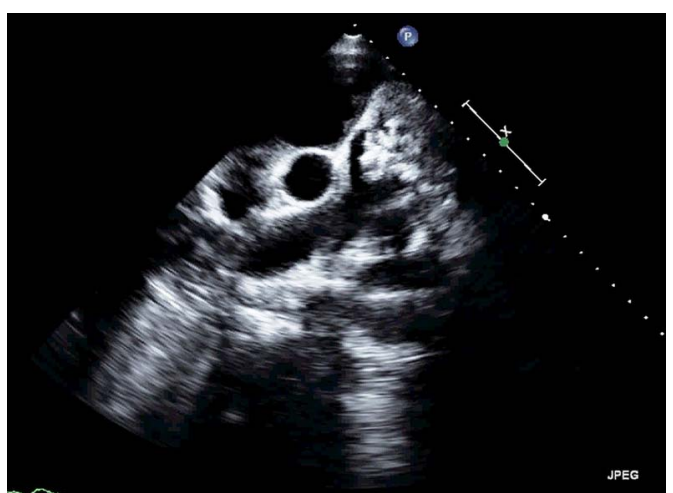

Figure 1 Parasternal short axis view at the level of the aortic valve showing the cauliflower-like deformed pulmonary valve.

deformed valve appeared echocardiographically convoluted like a 'cauliflower', which was an interesting echocardiographic appearance (figures 1-3, videos 1-4).

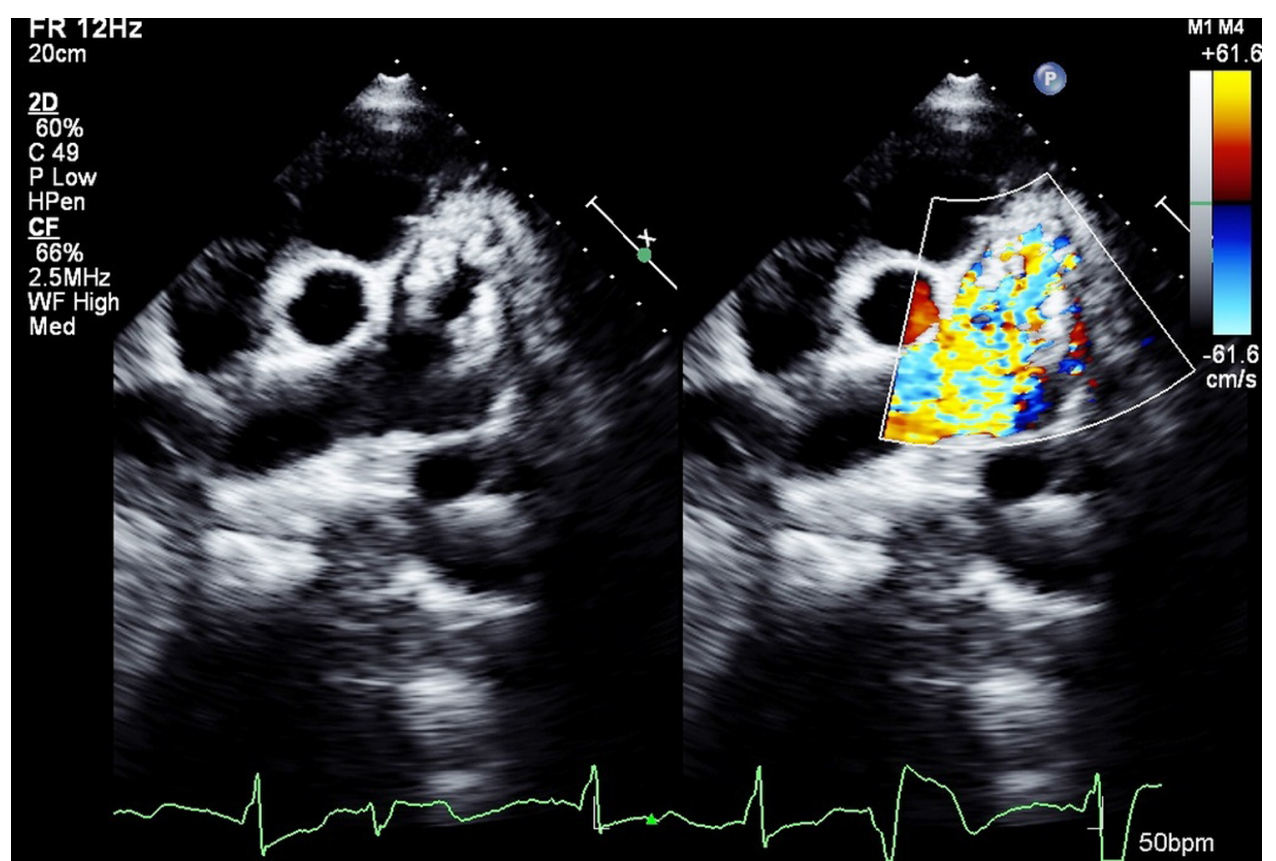

Figure 2 Parasternal short axis view at the level of the aortic valve with colour compare the cauliflower-like deformed pulmonary valve with severe pulmonary regurgitation. 


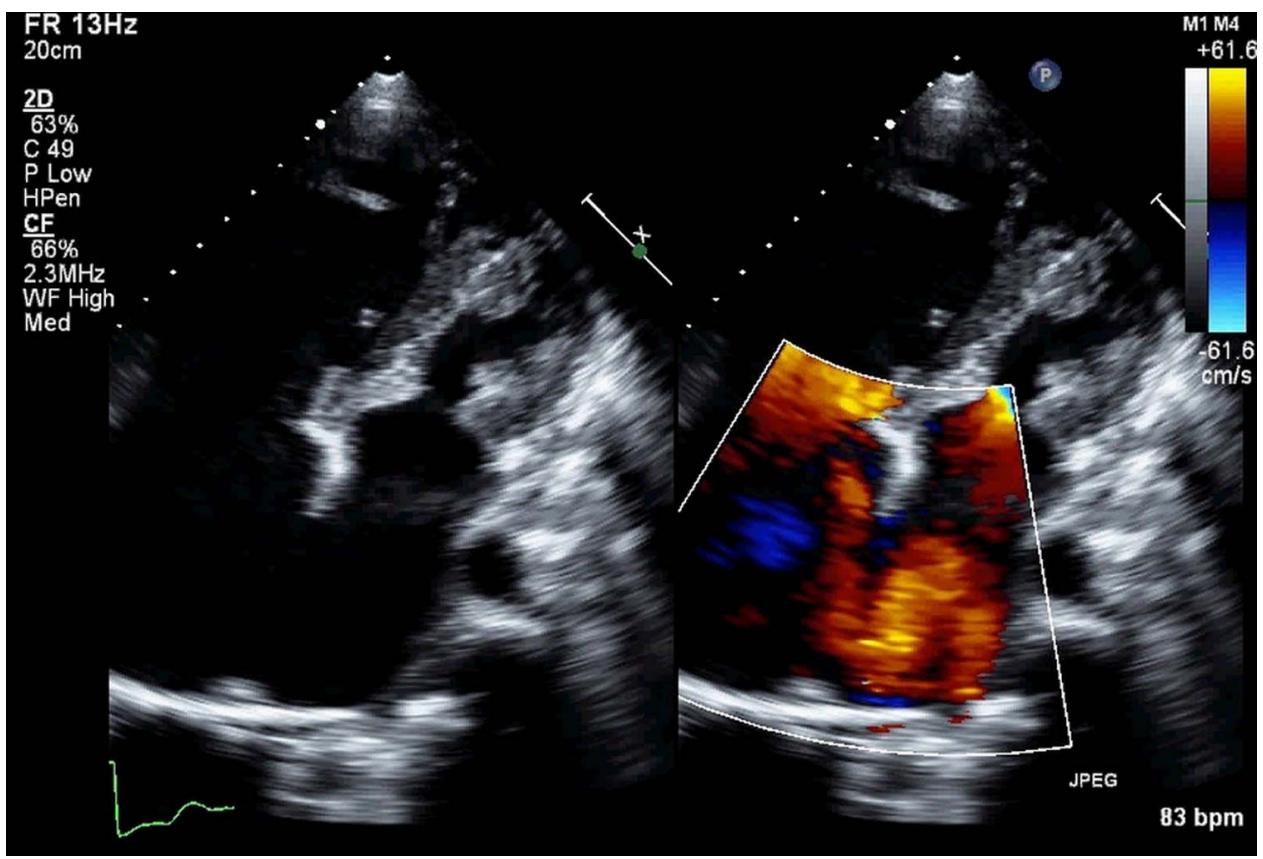

Figure 3 Apical four-chambered view with colour Doppler compare dilated right-sided chambers with a large atrial septal defect.

This patient underwent successful replacement of the pulmonary valve with a bioprosthetic valve and patch closure of the ASD. The patient has been stable and asymptomatic after 6 months of follow-up. The occurrence of infective endocarditis affecting the pulmonary valve in a case of ASD is extremely rare with only a few cases which have been reported ${ }^{1-3}$ and currently ASD does not form an indication for endocarditis prophylaxis.

G. morbillorum is often present as a commensal in the oropharyngeal area. It may rarely cause infections similar to other streptococci which include endocarditis and other invasive infections. A recent study reported it as the most common bacteria present in the teeth with cysts which are not responsive to repeated root canal treatments. ${ }^{4}$ Similar to other streptococci they are usually sensitive to commonly used antibiotics such as penicillin, ampicillin, cephalosporins, tetracyclines, chloramphenicol, macrolide antibiotics and vancomycin. ${ }^{5}$

The occurrence of a grossly deformed valve by a rare organism endocarditis causing severe pulmonary regurgitation makes this case extremely rare and the image interesting.

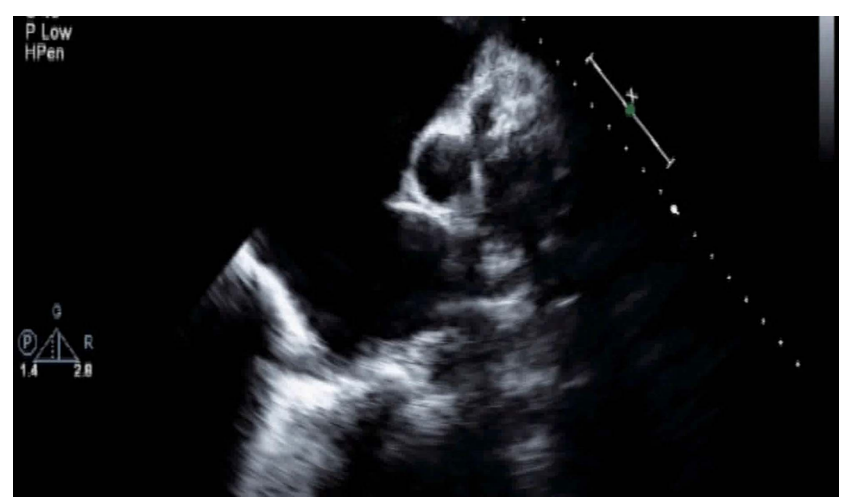

Video 1 Parasternal short axis view at the level of the aortic valve showing the cauliflower like deformed pulmonary valve.

\section{Learning points}

- Atrial septal defect although not included in the list of lesions requiring infective endocarditis prophylaxis can still be a cause of infection of the pulmonary valve which is subjected to damage due to increased blood flow.

- Organisms atypical for endocarditis can sometimes be a cause of significant valvular deformity requiring surgery which necessitates a vigorous attempt to culture and accurately identify such organisms.

- Endocarditis can cause deformation of the valves into abnormal shapes which can form an interesting echocardiographic appearance.

- Deformed valves can cause haemodynamically significant stenosis and regurgitation simultaneously which can necessitate valve replacement surgery.

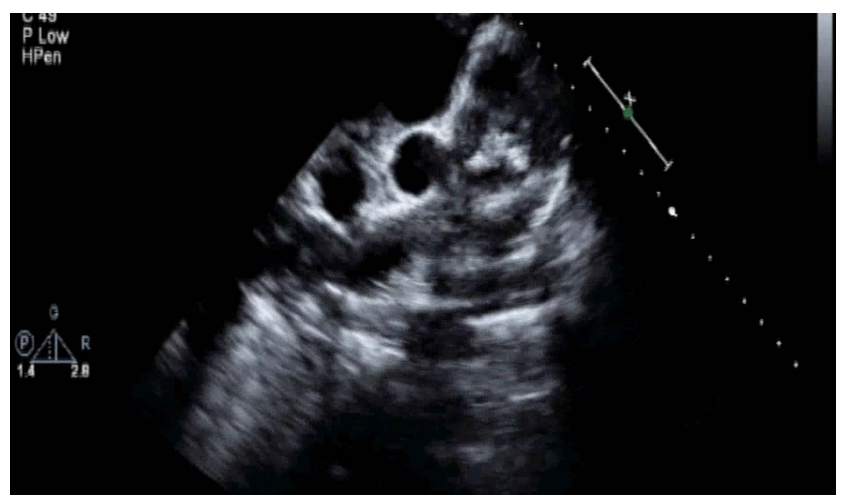

Video 2 Parasternal short axis view at the level of the aortic valve with colour compare showing the cauliflower like deformed pulmonary valve with severe pulmonary regurgitation. 


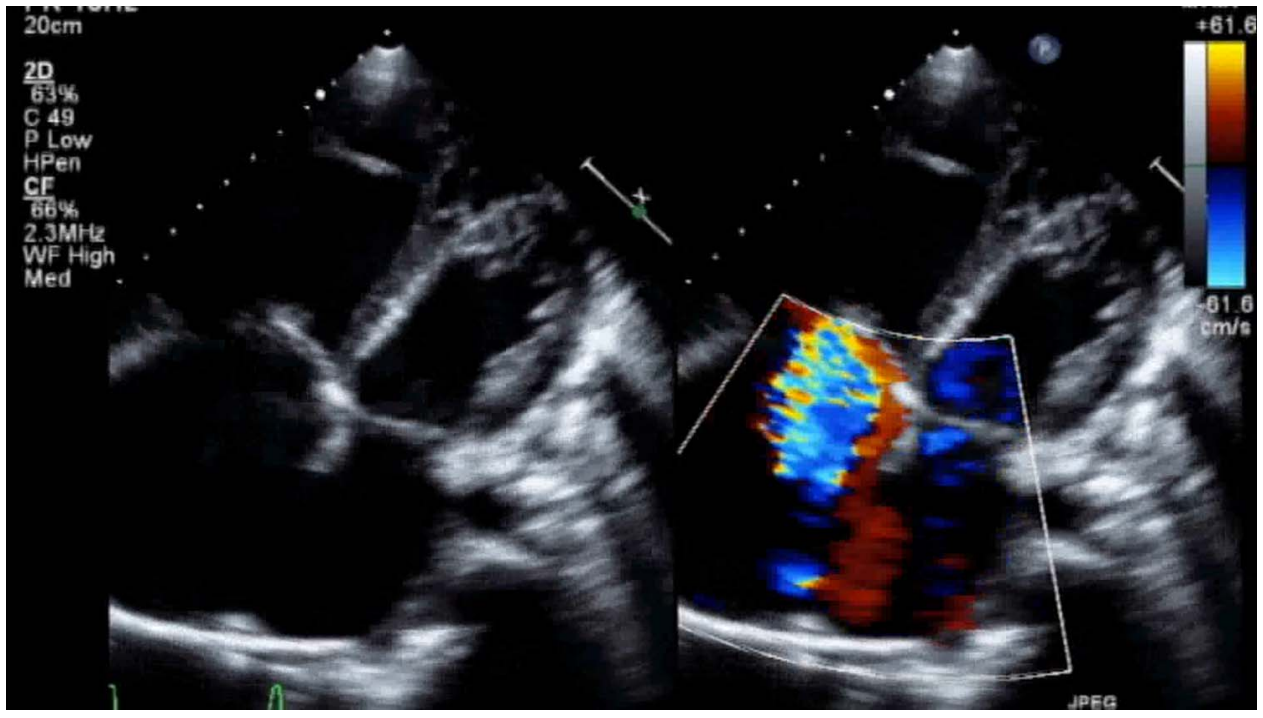

Video 3 Apical 4 chambered view showing dilated right sided chambers with a large atrial septal defect with colour compare showing a left to right shunt.

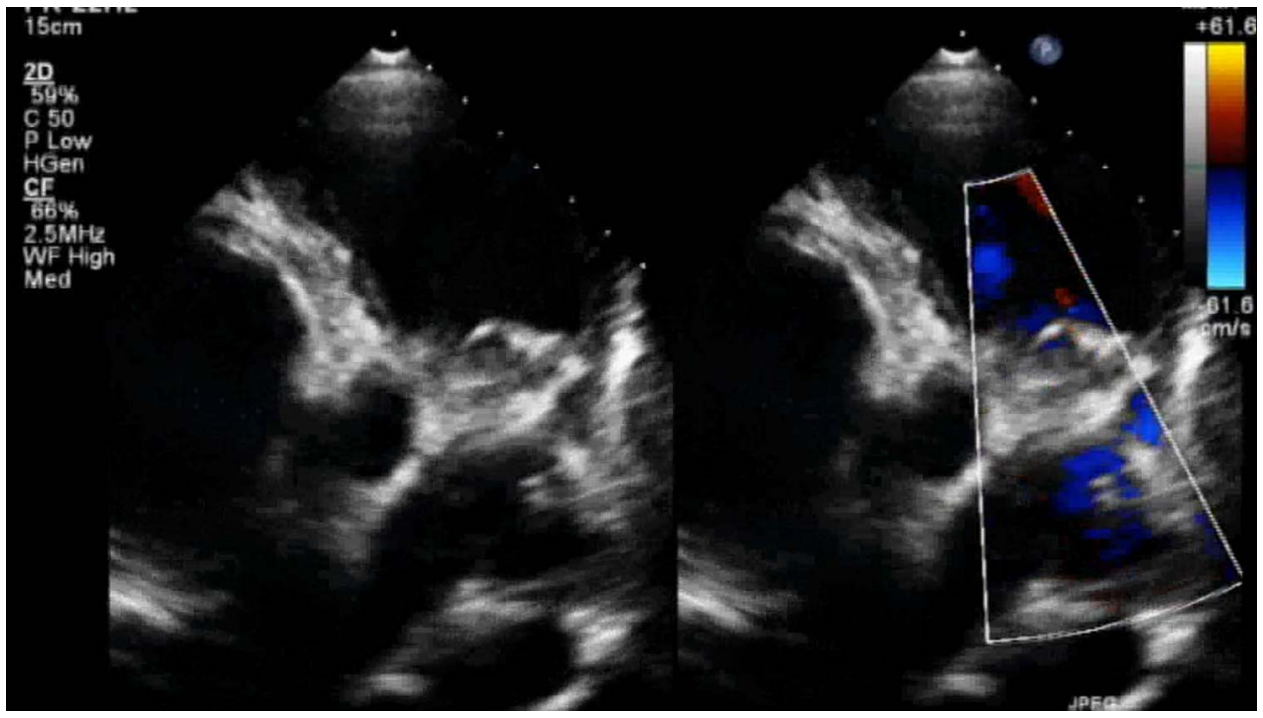

Video 4 Parasternal short axis view at the level of the aortic valve with colour compare showing the cauliflower like deformed pulmonary valve with severe pulmonary regurgitation.

\section{Competing interests None.}

Patient consent Obtained.

Provenance and peer review Not commissioned; externally peer reviewed.

\section{REFERENCES}

1 Aliaga L, Santiago FM, Marti J, et al. Right-sided endocarditis complicating an atrial septal defect. Am J Med Sci 2003;325:282e4.
2 Rahman A, Burma O, Felek S, et al. Atrial septal defect presenting with Brucella endocarditis. Scand J Infect Dis 2001;33:776e7.

3 Cremieux A, Witchitz S, Malergue $M$, et al. Clinical and echocardiographic observations in pulmonary valve endocarditis. Am J Cardiol 1985;56:610-13.

4 Signoretti FGC, Gomes BPFA, Montagner F, et al. Investigation of cultivable bacteria isolated from longstanding retreatment-resistant lesions of teeth with apical periodontitis. J Endod 2013;39:1240-4.

5 Ruoff KL. Miscellaneous catalase-negative, gram-positive cocci: emerging opportunists. J Clin Microbiol 2002;40:1129-33. 


\section{Images in...}

Copyright 2014 BMJ Publishing Group. All rights reserved. For permission to reuse any of this content visit http://group.bmj.com/group/rights-licensing/permissions.

BMJ Case Report Fellows may re-use this article for personal use and teaching without any further permission.

Become a Fellow of BMJ Case Reports today and you can:

- Submit as many cases as you like

- Enjoy fast sympathetic peer review and rapid publication of accepted articles

- Access all the published articles

- Re-use any of the published material for personal use and teaching without further permission

For information on Institutional Fellowships contact consortiasales@bmjgroup.com

Visit casereports.bmj.com for more articles like this and to become a Fellow 